\title{
El Conflicto ACtuAL Desde el Pasado \\ COMO ORIENTACIÓN PARA EL FUTURO
}

Cuatro son los ejes temáticos que sobresalen en los artículos que componen este Anuario de 2018: uno de ellos está centrado por el análisis de conflictos de largo recorrido para los que los acontecimientos sociales de un año (y su análisis) tan sólo representan una fase; otro de los ejes tiene que ver con conflictos en los que sobresale la cuestión "femenina", ya sea porque son las mujeres las víctimas principales de las condiciones que han conformado el conflicto o porque es la visión feminista y de género la que articula "de otro modo" el conflicto; en el tercero, la disputa principal del conflicto gira en torno al consumo, producción o distribución de los recursos naturales que, aunque concreta y territorialmente localizados, subraya la cuestión actual más urgente sobre cómo los humanos interactuamos en el medioambiente natural y, finalmente, el eje que tiene que ver con los procesos conflictivos que marcan los límites y/o los enemigos reales de la Democracia. 
En los trabajos que presentamos ninguno de los ejes señalados se hace explícito de manera autónoma, ni principal. Por ejemplo, nos vamos a encontrar con acontecimientos conflictivos de largo recorrido que ahora se expresan "a la manera" feminista o, también, con conflictos articulados alrededor de un bien básico y escaso para el que se demanda una organización orientada hacia "bienes comunes" y que, en general, aunque son manejados por las mujeres, éstas han quedado tradicionalmente fuera de los espacios de poder en los que se decide su propiedad y distribución, por tanto, hoy por hoy son las primeras víctimas de la escasez de tales recursos naturales. En definitiva, aunque cada artículo es ejemplo de más de uno de los temas señalados, los cuatro ejes constituyen las líneas en las que orientamos a iniciar la lectura de este número y representan, al mismo tiempo, el carácter singular de este año.

El orden de publicación de los artículos responde a los parámetros que establecen las secciones (asentadas en los últimos años de nuestra publicación) del índice de nuestra revista, y que fueron pensadas en función de la conexión entre las variables espaciotemporal (la coyuntura y procesos históricos en los que se insertan los acontecimientos analizados) y estructural (la forma y tipo de configuración societaria), conexión que es la normalmente considerada en el análisis típico de los conflictos sociales. 
- En la Sección I ofrecemos dos artículos, uno dedicado a la revisión de la cronología actualizada de la "crisis política de Ucrania". Una buena manera de aproximarse a la lectura del trabajo de Hanna Kulyk es captarlo globalmente como una denuncia sobre el silencio informativo que se está ejerciendo sobre muchos de los acontecimientos, actores, instituciones y agentes sociales que conforman este largo proceso conflictivo, y con orígenes e implicaciones tanto nacionales como internacionales. El segundo artículo de Anna Ramoneda aborda la actual cuestión de la gestión pública del bien común del agua en Cochabamba (Bolivia), presenta el repaso de las protestas y de iniciativas fracasadas, unas, y acertadas, otras, que se han dado durante los diecinueve años que, de una manera u otra, dura ya la Guerra del Agua. En este conflicto, además de la lucha por un bien escaso e imprescindible, destaca el perfil femenino que se impone tanto en la desigualdad social implícita en esta batalla, como en la desigualdad social que se deriva de sus injustos y provisionales resultados.

- La Sección II fue pensada para recoger todos los estudios sobre las estructuras, procesos y condiciones en los que se conforman los conflictos concretos, por lo que ofrecemos un trabajo de Cristina Ramirez en el que se repasa (mediante una cronología de los acontecimientos) "El desarrollo de los proyectos mineros y su impacto en las comunidades de su área de influencia" en Perú. En este caso las 
condiciones del conflicto se articulan alrededor de los intereses puramente empresariales y economicistas de los proyectos mineros frente $\mathrm{a}-\mathrm{y}$ en oposición de- las necesidades de las comunidades locales. Son estas comunidades las víctimas directas de la batalla: ven abolidos sus modos tradicionales de subsistencia, así como sus costumbres arraigadas de relación con la naturaleza. Pero también son el agente activo del conflicto y de resistencia. El repaso de esta cronología enuncia una incapacidad (a pesar del persistente enfrentamiento) para salir de la corriente mayor capitalista de la actual depredación neoliberal.

El carácter de las estructuras y de los procesos sociales concretos son lo único que puede explicar la existencia del Feminicidio allí donde se da. Esto es lo que pone de relieve Esther Pineda cuando (desde el ámbito de la actuación jurídica y con el recuento de datos estadísticos) subraya la dificultad que se ha dado en Argentina desde 2014 para llevar a cabo la urgente tipificación jurídica del feminicidio como delito. La autora denuncia las campañas que se están haciendo de neutralización y, por ende, de naturalización "jurídico-institucional" de los casos de asesinato masivo de mujeres.

Los análisis de Ramírez y Pineda refieren a dos casos acotados geográficamente, aunque ambos no son más que ejemplos de corrientes conflictivas "estructurales" que, como tales, replican en tiempos y espacios distintos y permanecen, por tanto, sin 
solución por el momento: mientras perdure una estructura de poder irrespetuosa con el territorio y las necesidades de sus habitantes habrá casos de estudio como el que se refiere aquí sobre la disputa por el cómo y quién realiza la explotación de los recursos naturales; así mismo, mientras perdure la estructura patriarcal se darán formas de abuso, maltrato y muerte de mujeres. Todos los conflictos estructurales expresan procesos que se articulan como padecimiento por el lado de las víctimas, pero también como resistencias y obstáculos para el cambio que, con seguridad, se dan por el lado de los beneficiados en las estructuras de poder establecidas. La lectura de casos como estos invita a hacer patente la necesidad de modificar de manera general y extensa las estructuras sociales existentes: el cambio al que se debe aspirar es de configuración societaria completa.

- La Sección III ofrece, en primer lugar, un balance de más de un siglo de avances y retrocesos en el desarrollo de la Democracia en México. El autor de este trabajo busca insertar en el curso de la historia política contemporánea los avatares actuales de la política y del gobierno de México para, desde allí, ofrecernos un balance del presente, este es su objetivo. La pregunta clave que se formula: ¿se ha abierto una nueva fase en la trayectoria política de México? o, dicho de otra manera, ¿realmente se han producido el punto de inflexión necesario para poner fin a una trayectoria histórica en la que la Dictadura reaparece una y otra vez? De la 
indagación de Philippe Dautrey no resulta una respuesta clara, pero el valor de su trabajo radica en mostrarnos cómo la sombra de la dictadura muchas veces se hace presente adoptando formas, más o menos severas o más o menos suaves, unas veces corporativistas, otras clientelares, y en muchas ocasiones camuflada por los ropajes externos de la Democracia. En su trabajo se da el trayecto que sigue el conflicto de largo recorrido en el que se enfrentan las dos fuerzas en oposición de la Dictadura y la Democracia.

Con similares objetivos de balance de la actualidad y de repaso histórico, César Santos Brunetto realiza su análisis sobre Brasil. En este caso también lleva a cabo un trabajo de exploración de la historia de más de un siglo para señalar los momentos de avance en la constitución de la República de este país, y los acontecimientos políticos principales de su abandono o retroceso. El balance en este caso es más concreto y pesimista: Brasil ha abierto una fase de desdemocratización perversa en el que se recoge el hilo histórico sustantivo y particular de su pasado que, por otro lado, encabalga bien con el lugar común que representa hoy la onda en ascenso de la extrema derecha internacional. Su recorrido histórico sirve para que, como lectores, podamos abrir el foco a la hora de afrontar una reflexión más precisa, en tanto que histórica e internamente contextualizada, sobre el presente de Brasil. 
Finalizamos esta sección con un trabajo realizado por Clara Camps. En su caso realiza un balance y selección de acontecimientos de la protesta en España y Catalunya desde 2011 y tras el estallido de la Crisis Global. El valor de su trabajo radica en saber rastrear en la serie de acontecimientos de protesta (y de su reacción represiva asociada) el discurso, la interpretación y la acción "femenina" (lo que la autora denomina "cosmovisión feminista"). Su conclusión es que esta cosmovisión ha permeado, e irá permeando aún más, las formas y los objetivos de la política actual. Por otro lado, creemos que su trabajo —además de ser representación de la misma cosmovisión que trata de analizar-es una mezcla entre el análisis-denuncia y el activismo-denuncia, y esta mezcla es necesaria especialmente para pensar cómo los conflictos, además de representar el cambio social por cuanto son su antesala, incorporan los rumbos necesarios para el cambio, a los que el análisis puede contribuir a clarificarlos y reactivarlos. Consideramos, por tanto, que trabajos como éste pueden ser complementos adecuados del análisis académico estandarizado que, en el mejor de los casos, señala cuáles son las resistencias para el cambio, pero no los giros sociales que ponen luz sobre el camino a seguir. La indicación derivada es la siguiente: una cosmovisión feminista y antirepresiva parece que se está abriendo paso y permeando el campo entero de la disputa social, y la penetración completa de esta orientación en todos los aspectos 
de la vida en sociedad es, además de imprescindible por múltiples razones, cada vez más urgente.

- Como siempre, finalizamos nuestra publicación ofreciendo tres Reseñas sobre publicaciones centradas en dos de los temas que en la inmediatez del presente hoy nos preocupan: el ascenso de la extrema-derecha y de las desigualdades sociales.

María Trinidad Bretones 